\title{
Nos "limites" de Ferdinand de Saussure: Coseriu, Weinreich, Labov e Herzog
}

Maria Hozanete Alves de Lima Felipe Morais de Melo ${ }^{b}$

\section{Resumo}

Quando se pensa em Ferdinand de Saussure, ao lado da conhecida antonomásia do tipo "Pai da Linguística Moderna", logo vem à mente as "dicotomias saussureanas": sincronia-diacronia, lingua-fala e sintagma-paradigma. É possível que essa lembrança se estenda àqueles que jamais leram o Curso de Linguística Geral (CLG). Este trabalho investiga a compreensão de leitores de Saussure sobre ideias pontuais - interligadas às famosas dicotomias -, quais sejam, "mudança", "sistema" e "homogeneidade"; são leitores especiais, Coseriu (1979) e Weinreich, Labov e Herzog [WLH] (2006). Refletimos sobre ideias desenvolvidas em duas de suas obras: uma relação mais integrativa entre sincronia e diacronia proposta por Coseriu (1979); a integração entre sistema e heterogeneidade pensada por WLH (2006). Procuramos mostrar, contudo, que no próprio CLG (SAUSSURE, 1995) essa relação integrativa já estava posta, malgrado a própria noção de dicotomia e os recortes metodológicos impostos por Saussure para se estudar a língua e colocar a Linguística no seio das ciências tenham favorecido um olhar de não integração entre a noção de "sistema" $e$ "homogeneidade", por exemplo. Consideremos, para seguirmos as balizas tradicionais da Historiografia Linguística, apenas o Curso de Linguística Geral - como produto de um Saussure canônico, difundido e ortônimo, por menos ortônimo que, a rigor, possa ser considerado o autor de uma obra que encerrou, em seu fazimento, o potencial da apocrifia - deixando, por enquanto, em "silêncio" os manuscritos saussureanos, recentemente vindos a público.

Palavras-chave: Ferdinand de Saussure, Sistema e homogeneidade, Sincronia e diacronia.

\footnotetext{
a Professora do Departamento de Letras e do Programa de Pós-Graduação em Estudos da Linguagem da UFRN, hozanetelima@gmail.com.

b Professor de Língua Portuguesa e Literatura do IFRN, felipemorais_m@yahoo.com.br.
} 


\section{Considerações iniciais}

Nos mesmos rios entramos e não entramos, somos e não somos.

Heráclito

Há mais de cinco séculos antes de Cristo e mesmo antes de Sócrates, viveram dois filósofos cujas ideias priorizaram perfis opostos de "verdade". Para Heráclito de Éfeso, o real estava na mudança, na fluidez. Nos mesmos rios entramos (aparência), e não entramos (fato, porque o rio já não é o mesmo). Somos (aparência) e não somos ("verdade", porque a cada instante somos outros, transformados). Parmênides de Eleia, coetâneo de Heráclito, compreende que as variações é que são ilusórias, pois a essência da realidade se assenta na constância das coisas, em sua imobilidade. Isso tradicionalmente: Heráclito, a corrente; Parmênides, a firmeza. Aparentes aparências patenteiam os contemporâneos peripatéticos. Bocayuva (2010, p. 2), contudo, precisa as coisas assim:

O primeiro [Parmênides] foca a identidade do mesmo, acusando a ilusão do movimento e do não ser. O segundo [Heráclito] foca a transmutação do mesmo, acusando, por sua vez, a ilusão da particularidade e da fixidez. Ambos, porém, afirmam a unidade e mesmidade no e do princípio. [...] Eles não se contrariam. Participam, na verdade, da mesma conversa, aquela que procura descrever o princípio, chamado por ambos: phýsis. Mas como quem conversa amigavelmente, eles podem perfeitamente apresentar diferentes argumentos, e este é exatamente o caso deles.

De perto, nem tudo é tão simples; as ciências estão repletas de polarizações de pensamentos; costumeiramente, a ciência é lida pelas lentes dessa repleção. A nossa, a Linguística, desde a fundação...

É possível que não resulte inverossímil, aos que tiveram contato acadêmico direto com a graduação em Letras, a seguinte impressão: quando se pensa em Ferdinand de Saussure, ao lado da conhecida antonomásia do tipo "Pai da Linguística Moderna", logo vem à mente as "dicotomias saussureanas": sincronia-diacronia, língua-fala e sintagmaparadigma. E, até mesmo, é possível que essa lembrança se estenda àqueles que jamais leram o Curso de Linguística Geral 
${ }^{1}$ Consideramos, parafraseando a linguista francesa Claudine Normand (1995), que o CLG foi (e ainda o é) uma obra bem real e que tenha sido ela que produzira os efeitos também reais - em uma geração de pensadores. Este fato, historicamente demarcado, não pode ser obscurecido pela concepção atual de que a obra foi um produto fictício, manufaturada pelas habilidades filológicas de seus organizadores - gerada, primeiramente, por estudos de especialistas que, de maneira notável, compararam o CLG com os cadernos de alunos que frequentaram os cursos oferecidos por Saussure, na Universidade de Genebra (Cf. Godel, 1957); depois, pelas recentes descobertas, em 1996, de manuscritos do linguista que, para muitos, revelam o "verdadeiro" pensamento de Ferdinand de Saussure. Neste "entretempo", é ao CLG que Eugenio Coseriu, Uriel Weinreich, William Labov e Marvin I. Herzog fazem suas referências.
(CLG). Tais dicotomias, por vezes, podem ser pensadas sob um ponto de vista que as tomem por evidentes. Desta feita, lemos que na sincronia temos um sistema linguístico cuja estrutura pode ser observada e descrita; já diacronicamente, podemos observar, em uma linha temporal, as mudanças operadas no sistema. A questão, como sabemos, não é tão simples, pois qualquer mudança (ou variação), por exemplo, tem sob ela o funcionamento do sintagma e do paradigma (o que implica considerar a relação entre os elementos linguísticos). E esse (sintagma e paradigma) é o movimento da língua - seja ela vista na diacronia, seja observada pelas lentes da sincronia movimento que permite considerar pontos "homogeneizantes" no sistema, embora seja essencial explicitar em nome de que esta homogeneidade estaria sendo defendida ou a maneira pela qual compreendida.

Na historiografia linguística, encontramos duas grandes obras que retomam as noções de "mudança", "sistema" e "homogeneidade" presentes no CLG, buscando estabelecer uma relação mais integrativa entre sincronia e diacronia e a associação entre sistema e heterogeneidade. Em tais obras, sincronia/diacronia, sistema/heterogeneidade são considerados antinomismos do linguista suíço. Estamos falando de Sincronia, diacronia e história (1979), do brilhante linguista Eugeniu Coseriu, e de Fundamentos empíricos para uma teoria da mudança linguística (2006), dos estudiosos Uriel Weinreich, William Labov e Marvin Herzog (2006) - doravante, também,WLH. Procuramos mostrar, em nossa pesquisa, contudo, que, no próprio CLG (SAUSSURE, 1995), essa relação integrativa já estava posta, malgrado a própria noção de dicotomia e os recortes metodológicos impostos por Saussure para se estudar a língua e colocar a Linguística no seio das ciências tenham favorecido um olhar de não integração entre a noção de "sistema" e "heterogeneidade", por exemplo.

Consideremos, para seguirmos as balizas tradicionais da historiografia linguística, apenas o Curso de Linguística Geral (CLG) - como produto dum Saussure canônico, difundido e ortônimo, por menos ortônimo que, a rigor, possa ser considerado o autor duma obra que encerrou, em seu fazimento, o potencial da apocrifia - deixando em "silêncio" os "manuscritos saussureanos", recentemente vindos a público e que se encontram na Biblioteca Nacional de Genebra (Suíça) ${ }^{1}$. 
Entendemos, ainda, que Coseriu e WLH concentram-se, também, apenas no CLG e não na série de estudos filológicos ou nos recentes manuscritos do linguista genebrino que vieram à público recentemente.

\section{Eugeniu Coseriu (1979): leitor de Saussure}

Não se pode negar que Saussure "dicotomiza" relações sintagmáticas e relações associativas, sincronia e diacronia, língua e fala, contudo, é preciso atentar - questão já notoriamente anunciada em qualquer livro que fale da Linguística e de Saussure - que essas divisões ocorrem metodologicamente. Sem se chegar aos manuscritos do linguista genebrino, estando na circunscrição mesmo de seu Curso de Linguística Geral, vamos percebendo, em vários momentos, reflexões presentes em toda a obra, anunciando a dificuldade em assumir um ponto de vista que ofereça ao linguista seu objeto de modo integral e o risco de estar mediante "um aglomerado confuso de coisas heteróclitas, sem liame entre si" (SAUSSURE, 1995, p. 16). Neste sentido, assumir a falta ou o excesso foi, para Saussure, o primeiro passo em direção ao estabelecimento do objeto da linguística. Vejamos, nas linhas seguintes, a postura assumida:

Qualquer que seja o lado porque se aborda a questão, em nenhuma parte se nos oferece integral o objeto da Linguística. Sempre encontraremos o dilema: ou nos aplicamos a um lado apenas de cada problema e nos arriscamos a não perceber as dualidades assinaladas acima [o som em sua dimensão fisiológica e na sua dimensão psíquica, a imagem acústica; o lado social e o lado individual da linguagem; sistema estabelecido e sistema em evolução], ou, se estudarmos a linguagem sob vários aspectos ao mesmo tempo, o objeto da Linguística nos aparecerá como um aglomerado confuso de coisas heteróclitas, sem liame entre si. (SAUSSURE, 1995, p. 16 - itálico nosso)

A consciência da complexidade dos fatos, ditas através do dilema imposto pelas dualidades ou de vários aspectos que engendram um aglomerado de coisas heteróclitas é colocada de início. Ferdinand de Saussure segue seu curso, elegendo novos polos para a fundação da ciência (sincronia, língua, sintagma, signo) e em um cenário bastante peculiar, haja vista que, como grande filólogo de formação, já havia experimentado outros espaços de pensamento científico sobre a linguagem, 
cujos horizontes eram sobremodo diferentes - a linguística comparativa e indo-europeísta. Um linguista rompendo, umbilicalmente, com um modo de investigação - crível e único, tanto para ele quanto para os maiores estudiosos do século XIX - que o tornara conhecido. Os organizadores do CLG nos oferecem, em relato, a dimensão peculiar desse linguista: “E, ademais, F. de Saussure era um desses homens que se renovam sem cessar; seu pensamento evoluía em todas as direções, sem com isso entrar em contradição consigo próprio" (CLG, 2012, p. 24-25).

Se, com os estudos mais modernos e novas pesquisas sobre a obra do linguista genebrino, a faceta "antiantinômica" vem tomando lugar de destaque, antes, habitava o silêncio face às leituras operacionalizadas no CLG.

O linguista romeno Eugenio Coseriu segue o pensamento saussureano, acentuando que o sintagma só se realiza pela potencialidade paradigmática da língua. Já a distinção dos "tempos da língua" (a diacronia), como sabemos, as "relações entre sincronia e diacronia" são objetos de um conjunto de ensaios coserianos conhecidos em sua séria obra Sincronia, diacronia e história (1979).

Nela, Coseriu (1979, p. 216) afirma que "a 'estaticidade', apesar do aparente paradoxo, não é um fato sincrônico, mas diacrônico: para comprová-la é necessário mover-se na linha do tempo". Assumimos, todavia, que no CLG, este pensamento coseriano já estava evidenciado. Senão, como entender o enunciado extraído da obra organizada por Bally e Secheye:

A cada instante, a linguagem implica ao mesmo tempo um sistema estabelecido e uma evolução: a cada instante, ela é uma instituição atual e um produto do passado. Parece fácil, à primeira vista, distinguir entre esses sistemas e sua história, entre aquilo que ele é e o que foi; na realidade, a relação que une ambas as coisas é tão íntima que se faz difícil separá-las (CLG, 1995, p. 16, grifo nosso).

Fica, nas linhas saussureanas, a posição de um linguista envolvido em uma complexidade que lhe reservará, na história, o epíteto de anti-historicista - com todos os sentidos que a palavra suporta. Seguindo ainda as linhas do CLG, podemos encontrar outros trechos ou ideias que nos permitem considerar não apenas como a sincronia só pôde ser pensada nos limites daquilo que lhe atravessa, a diacronia, já que a língua "é uma 
instituição atual e um produto do passado". Antes de Coseriu, Saussure, no CLG, afirma que o recorte "temporal" nos oferece sincronias, e, ainda mais, que a língua, à revelia da sincronia, se desloca na linha do tempo. Saussure bem o sabia, mas o que lhe interessava era como, na sincronia, uma língua funcionava. Não sem antes entender que as mesmas leis do funcionamento sincrônico poderiam explicar porque e como a língua sofreria mudanças.

\section{Weinreich, Labov e}

\section{Herzog (2006) x Coseriu (1979): leitores de Saussure}

As mudanças operam no interior do sistema, já que nada da língua existe fora dela. Essa forma de entender a mudança é fundamental para os fundamentos empíricos desenvolvidos para uma teoria da mudança linguística por Weinreich, Labov e Herzog (WLH) em sua obra clássica de 1968. Os autores partem do princípio (princípio que, empiricamente, já vinha sendo analisado por linguistas, principalmente por dialetólogos) de que o sistema linguístico se caracteriza pela heterogeneidade. Uma heterogeneidade não de caráter "acidental e particular" (SAUSSURE, 1995, p. 109), senão "coerente e integral de regras do tipo categóricas" (WLH, 2006, p. 103). Ainda para WLH, a “a associação entre estrutura e homogeneidade é uma ilusão. A estrutura linguística inclui a diferenciação ordenada dos falantes e dos estilos através de regras que governam a variação na comunidade de fala" (ibid., p. 125).

Ainda quanto aos princípios gerais apresentados por WLH, encontramos:

A mudança linguística não deve ser identificada com deriva aleatória procedente da variação inerente da fala. A mudança linguística começa quando a generalização de uma alternância particular num dado subgrupo da comunidade de fala toma uma direção e assume o caráter de uma diferenciação ordenada (WLH, 2006, p. 125).

Nos autores fica claro como é na sincronia (entenda-se, saussurianamente, no sistema, na estrutura linguística) que está o gérmen da diacronia, pelos fenômenos da variação. Também lemos, nos autores, o desenvolvimento, consciente ou não, da ideia de "mudança inserida no sistema" encontrada em Coseriu (1979) - publicada pela primeira vez em 1958, escrita, 
"no essencial, em 1955" (COSERIU, 1979, p. 11), ou seja, antes do trabalho de WLH, e que é referenciada pelos sociolinguistas apenas superficialmente numa nota de rodapé. Mas essa mesma ideia, por nossa percepção, já estava presente no Curso de Linguística Geral.

Tomemos as seguintes afirmações de Coseriu (1979): "estudar as mudanças não significa estudar 'alterações' ou 'desvios' [...] mas, ao contrário, estudar a consolidação de tradições linguísticas, ou seja, o próprio fazimento das línguas" (p. 94), "as modificações encontram os seus limites na funcionalidade do sistema" (p. 122) e "as mudanças [...] não são etapas mas momentos duma contínua 'sistematização'” (p. 234). Nota-se como Coseriu já expõe o caráter sistemático da mudança, atribuindo-lhe a razão de ser ao serviço prestado ao sistema, a fim de que este mantenha seu bom funcionamento; daí por que, sendo a mudança inerente ao sistema, as pessoas continuarem falando enquanto a língua muda, "isto é, enquanto passa a manutenção certamente por vias mais por períodos de menor sistematicidade" (WLH, 2006, p. 35).

Certamente, a abordagem de WLH segue suas trilhas próprias, num texto de cunho formalista e afeito à matemática estrutural gerativista, donde encontrarmos, por exemplo, uma fórmula que condensa a compreensão de uma regra variável (cf. WLH, 2006, p. 107); contudo, parece-nos lícito divisar a base conceitual chave sobre a qual os autores desdobram seus Fundamentos empíricos - repetimos: quer conscientemente, quer não, em Coseriu.

Há entre Coseriu (1979) e WLH (2006) outra semelhança: a premissa primordial de suas obras é desenrolada em oposição a ideias de Saussure, mais detidamente à oposição sincronia $x$ diacronia, o que acarreta, necessariamente, um rebate a outra dicotomia, língua $x$ fala (isso considerando menções diretas a esses níveis da dicotomia, posto que os polos das dicotomias saussurianas alinham-se relacionalmente em paralelo: línguasincronia-sintagma $x$ fala-diacronia-relações associativas).

Em Saussure, no CLG, certas passagens nos permitem acreditar que nem a associação entre sistema e homogeneidade, de que falam WLH, nem a patente distinção entre sincronia e diacronia, de que lhe acusa Coseriu, habitavam a consciência prolífica de Saussure. Daí resulta-nos permissível, conquanto possa gerar alguma controversa (que pode germinar mais da 
ideia tradicional que se ouve/lê sobre o CLG que de sua leitura), acreditarmos já aparecer em Saussure a ideia do sistema comportando a mudança.

As citações do CLG usadas por WLH na seção 1.2.1, denominada Saussure, com o intuito de ilustrar-nos como, para o linguista suíço, o sistema é homogêneo são, aos nossos olhos, em sua maioria, bastante reduzidas, impedindo a recuperação do sentido que possuem no contexto original, além de serem imprecisas quanto ao escopo almejado (a homogeneidade da língua), de modo que os trechos vão tomando as conotações exatas do novo ambiente textual em que foram postos. Destaquemos a única citação de WLH que alude a Saussure, e observemos como ela se comporta em relação ao texto do linguista genebrino:

Em particular, não há nada em sua teoria que pudesse acomodar uma língua heterogênea salvando-a ao mesmo tempo como um objeto legítimo da investigação sincrônica. 'A língua [...] é de natureza homogênea' (p. 32) (WLH, 2006, p. 56).

O contexto de origem, no CLG, ao qual WLH se referem, é, notavelmente, o excerto aqui destacado:

Enquanto a linguagem é heterogênea, a língua assim delimitada [como associação entre imagem auditiva e conceito, como a parte social da linguagem, como distinta da fala etc] é de natureza homogênea: constitui-se num sistema de signos onde, de essencial, só existe a união do sentido e da imagem acústica, e onde as duas partes do signo são igualmente psíquicas (SAUSSURE, 1995, p. 23)

É possível considerar que Saussure não está tratando da ausência de variação ou da mudança no próprio sistema, ideia a que WLH vão se opor. Ele atribui à língua uma natureza homogênea porque, diferentemente da linguagem (entendendo, no momento, a "fala"), nela (na língua) não interferem, quais elementos significativos, fatores de ordem fisiológica (alterações, por exemplo, nos aparelhos fonadores dos falantes), de gênero, de classe social, geográficos etc.; não haveria interferência no modo como ela funciona, internamente. Um exemplo são as relações paradigmáticas e sintagmáticas responsáveis pelo funcionamento linguístico (em uma língua particular e em todas as línguas de modo geral). São estes funcionamentos responsáveis, também eles, pelas mudanças, e pela variação linguística. 
As demais referências ao CLG utilizadas no capítulo 1 de WLH (2006) usadas a favor de estabelecer um contraponto entre Saussure e a proposta dos três autores, a rigor, não nos parecem demonstrar a suposta homogeneidade que Saussure confere à língua, não convencem como testemunhos de uma explícita exclusão da variação e da mudança.

Em terreno diametralmente oposto, é a seguinte percepção do linguista suíço que temos de encarar:

Um fato de evolução é sempre precedido de um fato, ou melhor, de uma multidão de fatos similares na esfera da fala; isso em nada debilita a distinção estabelecida acima [entre diacronia e sincronia]; esta se acha inclusive confirmada, pois na história de toda inovação encontram-se sempre dois momentos distintos: $1^{\circ}$ aquele em que ela surge entre os indivíduos; $2^{\circ}$ aquele em que se tornou um fato da língua, exteriormente idêntico, mas adotado pela comunidade (SAUSSURE, 1995, p. 115).

Afigura-nos, pelo fragmento, que Saussure tinha clara consciência do processo de variação implicado pelo processo de mudança, de forma análoga, ousaríamos dizer, à própria asseveração de WLH (2006, p. 126) "toda mudança implica variabilidade e heterogeneidade". Para se assumir, categoricamente, que o sistema para Saussure, qual descrito por WLH, é formado por uma homogeneidade, resta sempre procurar acompanhar em nome de que o termo "homogeneidade", na reflexão saussureana, é postulado.

Compreendemosque, na medida em quea heterogeneidade ordenada do sistema defendida por WLH (2006) esquematiza, em arquitetura gerativa, o princípio já patente em Coseriu (1979), que anuncia que o sistema contém a semente da mudança porque só pela mudança o sistema consegue validarse no tempo como sistema, não podemos nos furtar a uma nítida sensação de que em Saussure o sistema também funciona assim. Notem-se os extratos a seguir:

Sejam quais forem os fatores de alteração, quer funcionem isoladamente ou combinados, levam sempre a um deslocamento da relação entre o significado e o significante" (SAUSSURE, 1995, p. 89)

Esses fatos diacrônicos não tendem sequer a alterar o sistema. Não se quis passar de um sistema de relações para outro; a modificação não recai sobre a ordenação, e sim sobre os elementos ordenados (ibid., p. 100). 
Neste sentido, a mudança ocorre e entra no sistema; não modifica, contudo, a ordenação do sistema, exatamente porque, como dissemos acima, a mudança ocorre exatamente para manter a funcionalidade de sua ordem. Se WLH (2006, p. 36) defendem que "numa língua que serve a uma comunidade complexa (i. e., real), a ausência de heterogeneidade estruturada é que seria disfuncional", defendemos que ela é estruturada pelas relações que "correspondem a duas formas de nossa atividade mental, ambas indispensáveis para a vida da língua" (SAUSSURE, 2012, p. 171): as relações paradigmáticas e sintagmáticas.

Coseriu defende que

A língua real e histórica é dinâmica porque a atividade linguística não é falar e entender uma língua, mas falar e entender algo novo por meio duma língua. Por isso a língua se adapta às necessidades expressivas dos falantes, e continua a funcionar como língua na medida em que se adapta (COSERIU, 1979, p. 94).

Tais palavras de Coseriu nos lembram aquelas que visualizamos no capítulo sobre a mutabilidade e imutabilidade do signo linguístico quando, no CLG, está posta a incapacidade da língua defender-se "dos fatores que deslocam, minuto a minuto a relação entre o significado e o significante" como umas das consequências da arbitrariedade do tempo (SAUSSURE, 1995, p. 116). E também nos recorda que "o tempo altera todas as coisas; não existe razão para que a língua escape a essa lei universal" (ibid., p. 117). Indo mais adiante, interessa-nos uma questão de ordem semiológica, expressa em Saussure através do fato de que "o signo está em condições de alterar-se porque continua", compreendendo que

O que domina, em toda alteração, é a persistência da matéria velha; a infidelidade ao passado é apenas relativa. Eis porque o princípio de alteração se baseia no princípio de continuidade. (SAUSSURE, 1995, p. 115).

A compreensão de Saussure para inserir esse "fazimento" no sistema figurou-se-nos de uma sofisticação ímpar: a mudança, para o linguista, jamais irá interferir na ordem (entenda-se no bom funcionamento) do sistema porque, para o linguista, elas inserem-se no sistema, não no nível de relação entre os signos, mas num nível menor, do interior do signo, deslocando a relação entre o significante e seu significado. 
Destarte, podemos dizer que, antes de WLH e Coseriu, já em Saussure, a diacronia "passa" pela sincronia.

A verdade sincrônica parece ser a negação da verdade diacrônica e, vendo as coisas superficialmente, parecerá a alguém que cumpre escolher entre as duas; de fato, não é necessário; uma das verdades não exclui a outra (SAUSSURE, 1995, p. 112).

Ensaiamos finalizar os "limites" dessa "conversa" entre Coseriu, WLH e Saussure com a seguinte demanda do linguista genebrino, "A verdade sincrônica contradiz acaso a verdade diacrônica [...]? Não, pois isso seria ver a realidade pela metade" (op. cit., p. 113).

Enesse embate em busca da verdade acerca das realidades da língua, ensejados especialmente por essa última frase retirada do Curso, é inevitável a evocação a Drummond (1985, p. 70):

\author{
A porta da verdade estava aberta, \\ mas só deixava passar \\ meia pessoa de cada vez. \\ Assim não era possível atingir toda a verdade, \\ porque a meia pessoa que entrava \\ só trazia o perfil de meia verdade. \\ E sua segunda metade \\ voltava igualmente com meio perfil. \\ E os meios perfis não coincidiam. \\ Arrebentaram a porta. Derrubaram a porta. \\ Chegaram ao lugar luminoso \\ onde a verdade esplendia seus fogos. \\ Era dividida em metades \\ diferentes uma da outra. \\ Chegou-se a discutir qual a metade mais bela. \\ Nenhuma das duas era totalmente bela. \\ E carecia optar. Cada um optou conforme \\ seu capricho, sua ilusão, sua miopia.
}

\title{
4. Considerações finais
}

Ao final dessas breves reflexões teóricas, esperamos ter demonstrado como alguns dos limites atribuídos a Saussure são limitados, frutos mais da imagem tradicional que ao "pai da Linguística" se atribui do que, propriamente, ao conteúdo que podemos descerrar das páginas de seu CLG. A ideia da variação inerente à língua que os sociolinguistas trouxeram 
e as reflexões sobre a relação entre sincronia e diacronia que aduz Coseriu se, por um lado, foram tomadas como foco para desdobramentos da esteira "ciência da linguagem" ao longo do século XX, o que é fato, por outro, são ideias que também, a seu modo, já vinham se revelando entre as linhas do CLG e que podem nos dar mostras duma mente com menos limites do que os que a ela se lhe atribuem.

\section{REFERÊNCIAS}

BOCAYUVA, Izabela Aquino. et al. Parmênides e Heráclito: diferença e sintonia. Kriterion (UFMG. Impresso), v. 122, p. 399-412, 2010.

COSERIU, Eugenio. Sincronia, diacronia e história: o problema da mudança linguística. Rio de Janeiro: Presença; São Paulo: Universidade de São Paulo, 1979.

DRUMMOND, Carlos Drummond. Contos plausiveis. Rio de Janeiro: José Olympio, 1985.

GODEL, R. Les sources manuscrites du Cours de Linguistique Générale de Ferdinand de Saussure. Genève: Droz, 1957.

NORMAND, Claudine. "La coupure saussurienne", Linx [En ligne], 7, 1995,Disponível em: < http://linx.revues.org/1157 >. Acesso em: 21/07/2014.

SAUSSURE, Ferdinand de. Curso de Lingüística Geral. São Paulo: Cultrix, 1995.

SAUSSURE, Ferdinand de. Écrits de linguistique générale. Paris: Gallimard, 2002.

WEINREICH, Uriel; LABOV, William; HERZOG, Marvin. Fundamentos empíricos para uma teoria da mudança linguística. Trad. Marcos Bagno. São Paulo: Parábola, 2006. 


\section{Abstract \\ In the "limits" of Ferdinand Saussure: Coseriu, Weinreich, Labov and Herzog}

When we think of Ferdinand de Saussure, at the side of the known antonomasia from the sort of "father of modern linguistics", immediately the "saussurean dichotomies" come to mind: synchrony -diachrony; language-speech; syntagma-paradigm. It is possible this recollection extends to those who have never read the Course in General Linguistics (CGL). This paper reflects about the understanding of some readers of Saussure on certain specific ideas - all related to the famous dichotomies -, namely "change", "system" and "homogeneity"; they are special readers, Coseriu (1979) and Weinreich, Labov \& Herzog [WLH] (2006). We think about ideas developed in two of their works: a more integrative relationship between synchrony and diachrony proposed by Coseriu (1979); the integration between system and heterogeneity set by WLH (2006). We intend to show, however, that in the CGL itself (Saussure, 1995) this integrative relationship was already set, despite the very notion of dichotomy and the methodological cuts imposed by Saussure to study the language and put linguistics within the sciences have favored a look of not integrating the notion of "system" and "homogeneity", for example. We have considered, in order to follow the traditional mark of the linguistic historiography, only the Course in General Linguistics - as a product of a canonic, divulged and orthonymous Saussure, even for the less orthonymous that, strictly speaking, can be considered the author of a work that holds in its construction the potential of apocryphal writing - letting, for a while, in "silence" the saussurean manuscripts, recently come to the public eye.

Key words: Ferdinand de Saussure. System and homogeneity. Synchrony and diachrony. 